\title{
Notas teórico-metodológicas sobre o ordenamento territorial: Um ensaio político a partir das experiências de Volta Redonda e Cabo Frio
}

\author{
Guilherme Ribeiro' \\ Leandro Dias de Oliveira²
}

\section{Resumo}

O ordenamento territorial pode ser definido como toda e qualquer estratégia, ação ou movimento cuja manifestação prática-empírica resulte numa consequência territorial, mesmo que tal consequência não modifique concretamente / materialmente o espaço geográfico. Ao contrário do olhar que entende o ordenamento territorial como um processo eminentemente hegemônico, através de um esforço interpretativo-teórico inspirado pelas cidades de Cabo Frio e Volta Redonda, apontaremos as possibilidades políticas contidas no des-ordenamento territorial.

Palavras-chave: Ordenamento Territorial; Espaço Geográfico; Política; Volta Redonda; Cabo Frio.

\begin{abstract}
Territorial Planning can be defined as any action or movement strategy, whose practical manifestation-empirical results in a territorial consequence, even though such a result does not change materially / concretely geographic space. Unlike the look which means territory planning as a process eminently hegemonic, through an interpretative effort-theoretical inspired by cities of Cabo Frio and Volta Redonda, understand the alternative territory planning.
\end{abstract}

Keywords: Territorial Planning; Geographic Space; Policy; Volta Redonda; Cabo Frio. 


\section{Introdução}

Território é um espaço definido e limitado por e a partir de relações de poder (SOUZA, 1995), possuindo de maneira concomitante a dimensão força produtiva (QUAINI, 1979). O território é o fundamento do trabalho, o lugar da residência, das trocas materiais e espirituais e do exercício da vida (SANTOS, 2002); ele age como norma do espaço geográfico, estruturando ações e objetos em seu cotidiano (SANTOS, 1996).

Evidentemente, o território é uma síntese do diverso pois, por mais que o status quo insista em impor no território uma única e irrestrita ordem, esta traz consigo a possibilidade de uma outra ordem, uma "desordem" para o poder hegemônico. Assim, o território contém em cada parcela uma combinação ímpar que, para os dominados, representa o modo como estes recebem, acolhem esta ou aquela imposição. Seria o "contra-espaço" (MOREIRA, 2001, 2002), uma tentativa de contraponto aos interesses hegemônicos, uma manifestação popular que, se num primeiro momento não procura romper com o poder constituído, ao menos demonstra, abre caminhos para a possibilidade de outra apropriação do espaço geográfico.

Entre espaços e contra-espaços, afinal, como ocorre o ordenamento do território? Quais são suas principais características? Como ele se manifesta? Como tratá-lo no plano teórico-metodológico? Qual a importância da contribuição da Geografia em sua compreensão? Como articular espaço geográfico, território e des-ordem, categorias-chave que compõem seu "núcleo" epistemológico, revelando o sentido prático de sua manipulação? Estas e outras questões serão abordadas no presente trabalho, sem a pretensão de esgotá-las ou respondê-las integralmente, mas sim de estimo de construção da teoria e de proposições para debate.

\section{Possibilidades políticas e metodológicas do Ordenamento Territorial a partir de Volta Redonda - RJ}

O ordenamento territorial poderia ser definido, em linhas gerais, como sendo toda e qualquer estratégia, ação ou movimento cuja manifestação prática-empírica resulte numa consequência territorial, mesmo que tal consequência não modifique concretamente/ materialmente 0 espaço geográfico. Em geral, o ordenamento é enxergado como um mecanismo de regulação (BECKER, 1995) e estruturação (JUNG, 1972) do uso do território, outorgado (VEIGA, 1999), um direcionamento explícito do domínio hegemônico (MOREIRA, 2002). A criação de uma ordem hegemônica implica a constante vigilância para com o território, onde o processo de reestruturação é cabal 
para a manutenção do domínio, mas deixamos explícito que seu estudo não deve descartar a compreensão das forças resistentes e conflitantes ao processo.

Partiremos de alguns exemplos empíricos: uma greve de caminhoneiros pode não resultar na construção de melhores estradas entendida a estrada como um objeto geográfico, mas provocará uma nova dinâmica territorial, impedindo o escoamento da produção no tempo do capital, a chegada de pessoas aos seus locais de trabalho, engarrafamentos etc. Da mesma maneira, a ocupação de um latifúndio pelo MST envolverá o proprietário, que em defesa da propriedade privada acionará a polícia, que por sua vez agirá no intuito de remover os trabalhadores sem-terra daquela fazenda; uma parte da população poderá se deslocar até lá, emprestando apoio popular ao movimento, entre outras situações. Nesse panorama, pode não ter acontecido qualquer mudança material no espaço geográfico, mas uma "desordem" na "ordem" territorial vigente.

Assim, o des-ordenamento territorial não precisa, necessariamente, vir acompanhado de modificações materiais no espaço geográfico. Entretanto, todo e qualquer acontecimento desta natureza constitui-se num desordenamento do território. Imaginemos situações como a instalação de uma indústria, a construção de Brasília, a criação de aeroportos, a ligação entre cidades possibilitada por uma ponte, o erguimento de uma casa que servirá como sede da associação de moradores, entre outras. Uma indústria, uma cidade planejada, um aeroporto, uma ponte, uma casa, são objetos geográficos que trazem o sentido de uma classe, isto é, ou de um ordenamento ou de um desordenamento do território. Porque toda e qualquer construção de um objeto geográfico é carregada do significado dado pela classe que o criou.

O vocábulo possibilidade não tem sido repetido aleatoriamente, senão para ressaltar que a Geografia é uma ciência cuja capacidade de intervenção na sociedade é uma de suas potencialidades. Ora; se este campo do conhecimento tem no espaço geográfico do Homem sua preocupação central e sabendo que esse espaço tem sido um instrumento de manipulação com vistas à reprodução de interesses de uma minoria, não basta apenas enunciar tal fato, mas fundamentalmente sublinhar a possibilidade que os homens têm de construir uma outra alternativa à utilização daquele espaço, distinta do modelo vigente. Destarte, o ordenamento territorial é, também e simultaneamente, um desordenamento territorial, já que o território não se explica per se, mas sim através da ação humana, dos usos e abusos deste território. Dito de outra forma, o geógrafo não deve enxergar o território e manter seus olhos cerrados para o mesmo, mas sobretudo vislumbrá-lo tendo como interesse final, na verdade, o Homem; caso contrário, a ciência deixa de ser social e passa a ser ideal, um mero produto mental, e o ordenamento territorial deixa de ser uma escolha para ser um dado 
absoluto, uma certeza apodítica. Em suma, uma ideologia, que procura retirar a geohistoricidade dos seres.

Concretamente, é o ordenamento territorial um caminho para atingir determinados fins. Vejamos o caso da construção do desenvolvimento sustentável na cidade fluminense de Volta Redonda. Partiremos do entendimento que a concepção de desenvolvimento sustentável é uma nutriz de idéias dominantes, que se configura como uma ideologia camuflada sob o manto da "salvação da natureza". Ou seja, é um olhar para com a realidade, construído a partir de idéias dominantes, que oculta a luta de classes, transmitindo seus ideais como bem comum. O Desenvolvimento Sustentável se apresenta como reforço na manutenção da exploração dos países periféricos/subdesenvolvidos, através da gestão e regulação da natureza dos territórios dos países periféricos (OLIVEIRA, 2009). Elaborado através de grandes conferências e estudos, ele aporta como concepção norteadora no processo de ordenamento territorial em diferentes escalas.

Assim, Volta Redonda é uma cidade conhecida nacionalmente como "Cidade do Aço" porque tem a peculiaridade de ser formada a partir de uma indústria - a Companhia Siderúrgica Nacional (C.S.N.) - de grande importância histórica no decorrer do processo de industrialização do Brasil. De pequeno povoado predominantemente rural, a indústria gerou na cidade um grande crescimento demográfico nitidamente marcado pela segregação territorial, dando origem a conflitos por melhores condições de trabalho e sobrevivência. As diferenças observadas no espaço habitacional também se refletiam na dimensão dos impactos ambientais, onde as classes trabalhadoras ficavam mais suscetíveis aos problemas referentes aos diversos tipos de poluição - ar, água, solo, sonora etc. Afinal, a C.S.N. corresponde a um empreendimentos dos mais poluidores e um dos maiores causadores de danos ao meio ambiente.

Este quadro de problemas ambientais e sócio-econômicos desencadeou a elaboração de uma proposta de transformação a partir de uma reestruturação territorial, por intermédio da efetivação de certas ações. Diferentes atores sociais se esmeraram para a confecção de um plano estratégico, tendo como base principal o consenso global pós-ECO 92, que pregava uma nova forma de regulação tanto das relações sociais quanto da própria utilização da natureza.

É nessa conjuntura que nos últimos anos a cidade de Volta Redonda tem sido palco de um vultuoso processo de ordenamento territorial. Empreendido por diferentes atores sociais, vem alcançando visíveis resultados na implementação de estratégias edificadas à luz da sustentabilidade. Dentre elas, destacamos:

[1] o sucesso na gestão ambiental da C.S.N., que diminuiu de maneira contundente as poluições atmosférica, hídrica e do solo; 
[2] o desenvolvimento de projetos nas escalas local e regional visando a recuperação ambiental do Rio Paraíba do Sul;

[3] a criação de um plano de saneamento ambiental urbano, que desencadeou uma melhor otimização da utilização do lixo, através de monitoramento e reciclagem por parte do poder público;

[4] a arborização de áreas degradadas;

[5] a realização de estudos sistemáticos sobre o perfil sócio-econômico dos habitantes de Volta Redonda, paralelamente à capacitação de mão-deobra e o estímulo ao artesanato e produções de baixa tecnologia;

[6] a implementação de uma nova estética urbana, com investimentos maciços em novos objetos urbanos, com destaque para o Estádio da Cidadania.

Portanto, um gênero de ordenamento territorial assaz específico, voltado para a construção do desenvolvimento sustentável em Volta Redonda, significa:

[1] Um conjunto de práticas espaciais que compreende a implantação de novos objetos (áreas de proteção ambiental, estações de tratamento de água e esgoto, reflorestamento, instalação de fábricas ecologicamente corretas, entre outros) e novas ações (cursos de artesanato e jardinagem, gestão ambiental das empresas, reciclagem, arborização, educação ambiental ostensiva etc.);

[2] Uma nova ideologia capaz de agregar interesses difusos e eclipsar as dissonâncias de classe, que oculta sua gênese nas necessidades da C.S.N. de promover sua gestão ambiental e do Poder Municipal de recriar a cidade, promovendo a impressão de ser conseqüência dos debates travados no âmbito de eventos específicos da sociedade local.

Desta forma, não seria o ordenamento territorial um método? No caso acima delineado, o ordenamento territorial não serviu como método para a implementação do modelo de desenvolvimento sustentável em Volta Redonda? Destarte, o território é o instrumento, a matéria-prima, por assim dizer, enquanto o ordenamento territorial é a ação, o meio pelo qual o modo de produção capitalista agiliza a captura da mais-valia, tal como na construção de uma rodovia; põe em prática políticas de segregação da população, quando edifica "casas populares" longe do local de trabalho; seleciona esta e não aquela parcela do território para receber um determinado investimento; constrói uma capital para tentar manter distância de manifestações populares e revoltas políticas, como nos mostra o caso de Brasília; explora um dado "recurso natural" não é assim que o capitalismo concebe a natureza, 
enquanto um recurso? na orientação de somas vultuosas de dinheiro etc. Os exemplos são os mais variados, revelando as formas pelas quais os objetos geográficos se distribuem no território, ou seja, mostrando como o ordenamento territorial se manifesta.

\section{Possibilidades políticas e metodológicas do Ordenamento Territorial a partir de Cabo Frio - RJ}

De pouca valia será a Geografia construir uma epistemologia sólida e concisa acerca do espaço geográfico se não levar em consideração a sua produção. E refletir sobre esta produção significa identificar e detalhar os múltiplos sentidos dos agentes construtores e gestores dos recortes espaciais em suas múltiplas escalas de análise. É a partir de então que os geógrafos se defrontam com um outro problema: o de engendrar um método particular para o estudo dos agentes históricos sem, no entanto, que tal método seja uma mera coletânea dada pelo aporte da Sociologia, da Economia, da História. Esta é uma problemática central: o agir geográfico dos sujeitos (PORTO-GONÇALVES, 2006 [2002]). Ora; em se tratando da atuação dos sujeitos na produção do espaço, muitas vezes a nossa impressão é a de que o conhecimento geográfico estaria diluído em outras disciplinas. $O$ ordenamento territorial pode se apresentar como uma trilha para a constituição de uma identidade metodológica à Geografia do século XXI. Assim, quais os desdobramentos advindos do fato de tratarmos o ordenamento territorial como um método?

A tarefa não é das mais simples, decerto. Quando se constrói algo como uma universidade ou um shopping, há uma especificidade nestas construções que são próprias ao sentido das universidades e dos shoppings, uma lógica intrínseca a eles. Todavia, e aí é que reside um dos aspectos mais intrigantes e desafiadores, a produção do espaço geográfico ultrapassa de tal forma os limites a priori destes sentidos. Quais as consequências econômicas, políticas, sociais, culturais e espaciais que a instalação de um destes objetos pode gerar? Se essa questão parece de difícil resposta, ela é apenas uma parte, diríamos a metade, da interrogação que deve ser feita, no intuito de uma plena compreensão acerca do ordenamento territorial. A outra parte é a que diz respeito ao fato, aparentemente óbvio porém tampouco mais fácil de responder, de porquê a universidade e o shopping terem sido erguidos naquela fração do território. Em outras palavras, como o "ambiente construído" (SMITH, 1988 [1984]), como o entorno geográfico, em suma, como a geograficidade desta fração do território influenciou na decisão logística de uma certa empresa, condicionando-a a adotá-la como escolhida?

Há aqui, ainda que de modo implícito para um observador não-atento, uma questão referente às escalas. Tomemos um exemplo banal: uma indústria 
estrangeira decide instalar-se em um bairro de Niterói. Entretanto, este é um município do Estado do Rio de Janeiro que, por sua vez, pertence a uma região que se situa no âmbito de um território nacional. Ora; como conjugar estas diferentes escalas analíticas? O global, o nacional, o regional e o local em interação, sendo interdependentes e caracterizados por seus respectivos contextos, devem ser desvendados e desmembrados para entendermos o porquê da escolha de Niterói. Este é mais um complicador na labuta geográfica. Aqui, fazemos coro com Lacoste: a escala é um dos principais problemas epistemológicos da Geografia (LACOSTE, 1988 [1976]).

De qualquer forma, desde o início estamos ressaltando o caráter político do ordenamento territorial. Mas, recorrendo à História, vemos manifestações como a quebra das máquinas têxteis pelos ludditas na Inglaterra, interpretadas como as responsáveis pela demissão dos trabalhadores (HOBSBAWM, 1979); na França pós-revolução, vítimas de uma exploração que fazia com que o tempo fosse um instrumento de dominação atiravam contra os relógios nas torres (BENJAMIN, 1990 [1940]). Porque resgatamos tais acontecimentos? A resposta é bastante simples: será que o espaço geográfico tem sido interpretado pelo pensamento crítico como um instrumento político de dominação, erigido com o objetivo de garantir a reprodução das relações de produção? Será que o maior crítico do capitalismo esteve atento a isto? Em sua obra máxima, encontramos uma passagem bastante expressiva:

"Já a situação habitacional é fácil de entender. Qualquer observador desprevenido percebe que, quanto maior a centralização dos meios de produção, tanto maior o amontoamento correspondente de trabalhadores no mesmo espaço e, portanto, quanto mais rápida a acumulação capitalista, tanto mais miseráveis as habitações dos trabalhadores. Os 'melhoramentos' urbanos que acompanham o progresso da riqueza, a demolição de quarteirões mal construídos, a construção de palácios para bancos, lojas etc., desalojam evidentemente os pobres, expulsando-os para refúgios cada vez piores e mais abarrotados de gente" (MARX, 1975:764 [1867]).

Impressionante a sensibilidade espacial de Marx! A interpretação é inequívoca: ele vinculava diretamente espaço geográfico com a política habitacional e a economia capitalista, entendendo que o primeiro era manipulado pela classe dominante. Talvez não o tenha feito de maneira sistemática, convém lembrar, mas poucos motivos justificam o predomínio do historicismo no pensamento crítico, um historicismo cego para a Geografia, relegando o espaço geográfico a uma posição secundária e recôndita no seio do próprio marxismo (HARVEY, 1992 [1989]; SOJA, 1993 [1992]; GREGORY, 
1996). Atualmente, é mister que o materialismo seja não apenas histórico, mas também geográfico, numa junção espaço- temporal que potencializará não só o marxismo, mas abrirá a perspectiva para uma Geografia crítica de fato. Que destruam o espaço, então, visando dar seqüência à atuação dos ludditas e revolucionários franceses.

Continuando em Marx, quando este diz que o salário é um engodo, mutatis mutandi podemos dizer o mesmo da paisagem. A paisagem produz uma verdadeira sedução visual, que acaba por embaralhar aquilo que é forma e aquilo que é conteúdo. Nos referimos aos prédios luxuosos, aos shoppings coloridos com diversos matizes, aos centros de determinadas cidades que encantam pela arquitetura high-tech mas que, na verdade, tentam de uma forma ou de outra tornar invisíveis, "maquiar" a pobreza de seus subúrbios. Segundo Cosgrove, durante a Revolução Francesa certos quadros ingleses exibiam pinturas de paisagens tranqüilas, com cenas que mostram uma determinada trivialidade nos trabalhadores rurais colhendo em abundância, bastante felizes, as produções agrícolas (COSGROVE, 1998). Essa era a imagem que a oligarquia inglesa queria hegemonizar, a fim de que as lutas, dificuldades e insatisfações dos trabalhadores desaparecessem, dando lugar a uma sociedade harmônica e feliz.

Por conseguinte, como podemos negligenciar a espacialidade da vida social ou, pior ainda, considerá-la um elemento neutro e desprovido de caráter político e econômico na reprodução do "modelo civilizatório" capitalista? Se mencionarmos a natureza, por exemplo, observaremos que no Brasil ela é apregoada no imaginário coletivo tanto interna quanto externamente, caracterizando o já tão batido - porém vigoroso - discurso do país tropical, abençoado pela natureza plena, conformando um povo alegre e festeiro (CHAUÍ, 2000). É a naturalização do Homem e a despolitização da natureza, projeto elaborado com zelo pela inteligentsia da burguesia nacional. Todos estes elementos apenas corroboram a dimensão política do ordenamento territorial, parcelando-o aqui e ali de modo a potencializá-lo o máximo possível, racionalizando seu uso e des-racionalizando a compreensão dos trabalhadores. Um dos caminhos para isso? Dissolvendo o poder (LÉBRUN, 1981) por intermédio da imagem.

Podemos também utilizar como exemplo empírico o caso da cidade fluminense de Cabo Frio. Inserida na Região das Baixadas Litorâneas (especificamente na sub-região denominada, mercadologicamente, de "Costa do Sol"), durante grande parte de sua história apresentou economia baseada na atividade pesqueira e na extração do sal (que vem, atualmente, recebendo novo impulso). Contudo, atualmente, Cabo Frio tornou-se uma cidade média dinâmica, com grande expansão imobiliária. Verificamos nas últimas décadas um claro processo de migração de empresas, população e recursos em direção às cidades médias brasileiras, configurando um quadro que $M$. Santos denominou "dissolução da metrópole" (SANTOS, 1993). Na disputa pela captação destes recursos, são produzidas imagens sedutoras, em um 
agressivo city marketing.

Assim, em Cabo Frio, o investimento na paisagem é um amálgama que envolve uma construção ideológica de "cidade-com-qualidade-de-vida" e a adequação da cidade aos interesses de comercialização do espaço através de um ordenamento territorial com base no turismo. Através de slogans como Cabo Frio: A cidade mais limpa do Brasil ou Cabo Frio:

Cidade abençoada por Deus, reproduzidos em diversos locais, este ordenamento cria um mecanismo de inculcação baseado na paisagem. Além destes slogans, a prefeitura também tem investido na limpeza urbana de modo "paisagístico" instalando a "setorização cromática", que divide a cidade em conjuntos de bairros limítrofes demarcados por uma só cor - laranja, amarelo, verde, azul etc. - a ilustrar fachadas, meios-fios, lixeiras, criando micro-regiões organizadas para a limpeza e enfatizando tal prática para a população residente e visitante lançando mão de uma profusão de cores.

De qualquer maneira, a linguagem dos símbolos contida na paisagem torna-se adequada às necessidades do capital; o vício consumista está presente nos detalhes das orlas, nos shoppings e no boulevard Canal, com a paisagem sendo transformada numa grande vitrine alimentada por um discurso que mistura marketing e semiótica. Se enquanto matriz a cidade permanece um espaço de lazer e descanso, a outrora marca característica das salinas e das dunas vai sendo substituída pelos decks e boulevares (vide BERQUE, 1998). Por fim, acabamos perdendo a noção de que a paisagem é portadora e reprodutora de valores sociais. Completa-se então o ciclo D-M-D': a paisagem torna-se mercadoria e é consumida, gerando riquezas num ciclo indeterminável (MOREIRA, 1993). Surge então a "imagem do sonho" — a Ideologia - onde a luta desaparece e emerge a crença na realidade delineada pela classe dominante (OLIVEIRA, 2007; OLIVEIRA e MASCARENHAS, 2007; RIBEIRO e OLIVEIRA, 2010).

Contudo, a poucos quilômetros do centro, em bairros pobres como Jardim Esperança, Guriri e Boca do Mato, encontramos o avesso do ordenamento territorial hegemônico ou o des-ordenamento territorial, onde emerge uma ordem territorial bastante diferente, menos preocupada com a forma e expondo para quem quiser ver os problemas sociais típicos dos países periféricos: violência, pobreza, exclusão, falta de oportunidades. Eclipsadas por caminhos turísticos, existem favelas bem próximos ao centro da cidade que nos lembram que a realidade é classista e que "modelos urbanos" pautados em trabalho abstrato e espaço abstrato são altamente segregadores.

Nesse sentido, o pensamento crítico proveniente do marxismo tem muito a aprender com Michel Foucault. Em Securité, Territoire, Population ao articular o soberano ao meio, ele identifica técnicas políticas endereçada ao meio. Essas técnicas diziam respeito à segurança, à arquitetura, à boa circulação de modo geral (FOUCAULT, 2004 [1978]).

Quando investigou a problemática do poder no artigo Soberania $e$

TAMOIOS. ANO V. № 1, 2009 - ISSN 1980-4490 
Disciplina, numa relação estreita deste com a verdade e o direito, engendrou interrogações instigantes como "De que regras de direito as relações de poder lançam mão para produzir discursos de verdade?" (FOUCAULT, 1979:179). Assim, ele acabou por "descobrir" o território e deixar, à disposição da Geografia, uma série de elementos para que, por analogia, possamos promover uma reflexão sobre seu ordenamento.

$O$ primeiro deles trata do enlace entre o direito, representando a verdade, e o território, simbolizando o poder constituído. O direito é simbolizado pela Constituição Federal, ícone da verdade da nação; é o objeto teórico que rege as relações nacionais. Ora; mas a Constituição, as leis, regras e normas nela contidas carecem, para fazer valer a verdade, de uma concretude material, de manifestações que ultrapassem o plano teórico e se façam presentes no plano empírico. Esse empírico é o território, locus onde a "verdade" será posta em prática através das prisões, dos hospitais, dos asilos, entre outros. Ora; a regulação da lei, que visa justamente impor a ordem, só se concretiza por intermédio do ordenamento territorial que, aqui e ali, garantirá de fato a reprodução do modelo hegemônico.

Uma segunda analogia a ser feita a partir da abordagem foucaultiana deve ser investigada quando de seu interesse pela face externa do poder, isto é, o poder não-jurídico, algo que não se constitui apenas num monopólio do Estado. É neste momento em que ele se depara novamente com o território, revelador das formas e mecanismos pelos quais o poder se concretiza, movimentando num arranjo que reúne redes e malhas, emprestando a racionalidade necessária à irracionalidade burguesa:

"procurei examinar como a punição e o poder de punir materializavam-se em instituições locais, regionais e materiais (...) O poder deve ser analisado como algo que circula, ou melhor, como algo que só funciona em cadeia. Nunca está localizado aqui e ali (...) funciona e se exerce em rede." (idem, pp.180-181, grifo nosso).

Poder, Estado, leis, ordem... O ordenamento territorial, enquanto instrumento prático de ação do status quo, vem servindo como promotor da:

(i) repressão, através das prisões e dos hospícios, p.ex., mas também por meio do combate a trabalhadores grevistas ou a "invasores" de latifúndios, sempre visando estabelecer a ordem;

(ii) segregação, onde a classe dominante seleciona determinadas parcelas do território seja para o seu lazer, seja para sua residência, num discurso onde a burguesia vive aqui e o proletariado vive bem longe, desenhando no território centros e periferias numa vã tentativa de evitar o 
encontro, o embate;

(iii) dominação, onde a posse da propriedade privada se apresenta como algo natural, levando a minoria da população a se apoderar do poder e, conseqüentemente, trazendo consigo o direito de legislar sobre os rumos da maioria. Quem assume o território detém o poder, reprimindo, segregando e dominando a classe trabalhadora no intuito de manter a ordem.

Entretanto, em todos estes casos, o ordenamento contém, em si, o germe de um desordenamento. Ou seja, simultaneamente ao fato de que existe um ordenamento hegemônico, há ao lado deste um "desordenamento" que poderíamos denominar também de contra-ordenamento hegemonizado, que busca, aqui e ali, resgatar seu direito à cidade, que no fundo é um resgate do Homem enquanto projeto (LEFEBVRE, 2001 [1968]). O ordenamento hegemônico quer impor, a todo custo, a identidade, seja nos fazendo crer que os homens são iguais perante a lei, seja por intermédio da ilusão de que a relação patrão- empregado é uma relação igualitária, que beneficia a todos; por sua vez, o "desordenamento" vem à tona, sobretudo, carregando em seu âmago a diferença, trazendo para a cidade os expropriados do campo, os favelados para o asfalto, a pobreza se revelando enquanto a face mais vil da riqueza, manifestando com isso a necessidade da classe trabalhadora de um novo conteúdo social que possa resgatar o projeto anteriormente citado.

\section{Um debate aberto}

Os geógrafos devem permanecer atentos a dois processos em curso: a naturalização do território e a neutralização do espaço geográfico, numa leitura que admite o primeiro como algo que pertence a um povo, e não a uma minoria que dele se apodera; e o segundo como se fossem objetos neutros e desprovidos de significados políticos, meros reflexos sem maiores conseqüências sociais. É como se os objetos não afetassem os sujeitos, desconhecendo a inércia dinâmica, o prático-inerte de que nos falava Santos (SANTOS, 1978; RIBEIRO, 2004a).

$\mathrm{Na}$ medida em que um novo conteúdo social se apresenta diante de nossos olhos desenvolvimento sustentável, globalização, capital especulativo, atomização social, novas tecnologias, nada mais válido do que reconhecer a complexidade do ordenamento/desordenamento territorial, sua face repressora, segregacionista e dominante; do espaço geográfico enquanto uma reunião de objetos que visam atender às demandas do modo de produção capitalista, isto é, onde o espaço geográfico passa a ser um meio para a continuidade da classe hegemônica. Mas também para, de modo otimista, 
rejeitar a imposição de um ordenamento único, propondo um desordenamento universal parafraseando Santos (SANTOS, 2000) que rompa com o panorama atual e engendre uma nova alternativa.

\section{Notas}

1- Doutor em Geografia pela UFF (ênfase em Ordenamento Territorial UrbanoRegional), com doutorado sandwich pela Universidade de Paris - Sorbonne (Paris IV). Prof. Adjunto I de Geografia do Instituto de Ciências da Sociedade e Desenvolvimento Regional da UFF - Campos dos Goytacazes.

2- Mestre em Geografia pela UERJ e Doutorando em Geografia pela UNICAMP. Professor Assistente do Curso de Geografia do Departamento de Geociências da UFRRJ - Universidade Federal Rural do Rio de Janeiro, Seropédica - RJ.

\section{Referências Bibliográficas}

BARRIOS, Sonia. A produção do espaço. In: SANTOS, Milton, SOUZA, Maria Adélia de (orgs.). A Construção do Espaço. São Paulo: Nobel,1986.

BECKER, Bertha K. A Geopolítica na Virada do Milênio: Logística e Desenvolvimento Sustentável. In: CASTRO, Iná E.; GOMES, Paulo C. da C.; CORRÊA, Roberto L. (orgs.) Geografia: Conceitos e Temas. Rio de Janeiro, Bertrand Brasil, 1995.

BENJAMIN, Walter. Sobre o Conceito da História. Revista Teoria \& Política. São Paulo: Brasil Debates, 1990 [1940].

BERQUE, Augustin. "Paisagem-marca, paisagem-matriz: elementos da problemática para uma Geografia Cultural." In: CORRÊA, Roberto Lobato e ROSENDAHL, Zeny (orgs.). Paisagem, Tempo e Cultura. Rio de Janeiro, EdUERJ, 1998.

COSGROVE, Denis. "A Geografia está em toda parte: cultura e simbolismo nas paisagens humanas." In: CORRÊA, Roberto Lobato e ROSENDAHL, Zeny (orgs.). Paisagem, Tempo e Cultura. Rio de Janeiro: EdUERJ, 1998.

FOUCAULT, Michel. Soberania e Disciplina. In: FOUCAULT, Michel. 
Microfísica do Poder. Rio de Janeiro: Graal (1979).

—. Securité, Territoire, Population. Paris: Seuil/Gallimard, 2004 [1978].

GREGORY, Derek. Teoria social e geografia humana. In: GREGORY, Derek, MARTIN, Ron, SMITH, Graham (orgs.). Geografia Humana: Sociedade, Espaço e Ciência Social. Rio de Janeiro: Jorge Zahar Editor, 1996.

HAESBAERT, Rogério. O mito da desterritorialização. Rio de Janeiro: Bertrand Brasil (2004).

HARVEY, David. Condição Pós-Moderna: uma pesquisa sobre as origens da mudança cultural. São Paulo: Loyola, 1992 [1989].

HOBSBAWM, Eric. A Era das Revoluções: 1789-1848. Rio de Janeiro: Paz e Terra (1979). JUNG, Jacques. Ordenación del Territorio. In: JUNG, Jacques. La Ordenación del Espacio Rural: Una ilusión económica. Madri, Instituto de Estudios de Administración Local, 1972. KANT, Immanuel. Estética Transcendental. In: KANT, Immanuel. Crítica da Razão Pura. São Paulo: Martin Claret, 2002 [1781].

LACOSTE, Yves. A Geografia: isso serve, em primeiro lugar, para fazer a guerra. São

Paulo: Papirus, 1988 [1976].

LEFEBVRE, Henri. O Direito à Cidade. São Paulo: Centauro, 2001 [1968].

. A Revolução Urbana. Belo Horizonte: Editora da UFMG, 1996 [1970].

LÉBRUN, Gerard. O que é Poder. São Paulo: Brasiliense, 1981.

MARX, Karl. O Capital. Livro 1, Volume 2. Rio de Janeiro: Civilização Brasileira, 1975 [1867].

, ENGELS, Friedrich. A Ideologia Alemã. São Paulo: Editora Moraes, s/d [1846].

MOREIRA, Ruy. "O racional e o simbólico na Geografia" In: SOUZA, Maria Adélia A.; SANTOS, Milton; SCARLATO, Francisco C.; ARROYO, Mônica (orgs.). O Novo Mapa do Mundo. Natureza e Sociedade de Hoje: Uma Leitura Geográfica. São Paulo: HUCITEC, 1993.

- A Diferença e a Geografia (O ardil da identidade e a representação da diferença na Geografia). GEOGRAPHIA, Revista do Programa de Pós- 
Graduação em Geografia da UFF. Niterói/Rio de Janeiro, UFF/EGG, Ano I, no I, 1999.

.As Categorias Espaciais da Construção Geográfica das Sociedades. GEOGRAPHIA, Revista do Programa de Pós-Graduação em Geografia da UFF. Niterói/Rio de Janeiro, UFF/EGG, Ano III, n 5, 2001.

. O Espaço e o Contra-Espaço: Sociedade Civil e Estado, Privado e Público na Ordem Espacial Burguesa. In: Território Territórios/Programa de PósGraduação em Geografia-PPGEO-UFF/AGB - Niterói, 2002.

NEWTON, Isaac. O Peso e o Equilíbrio dos Fluidos. In: NEWTON, Isaac. Princípios Matemáticos. Óptica. O Peso e o Equilíbrio dos Fluidos (Coleção Os Pensadores). São Paulo: Abril Cultural, 1979.

OLIVEIRA, Leandro Dias de. A Construção do Desenvolvimento Sustentável na Cidade de Volta Redonda: Um Estudo sobre Reestruturação do Território e Ideologia, 2006. Dissertação (Mestrado em Geografia). Departamento de Geografia do Instituto de Geociências, Universidade do Estado do Rio de Janeiro, Rio de Janeiro, 2006.

O Controverso Conceito de Paisagem: Uma Experiência Teórico-Metodológica no Ensino de Geografia. In: VI Encontro Nacional de Ensino de Geografia: Fala Professor, 2007, Uberlândia. Concepções e Fazeres da Geografia na Educação: Diversidade em Perspectivas. Uberlândia: AGB, 2007.

Teses sobre o Desenvolvimento Sustentável. Revista lluminart, v. 1, p. 242256, 2009.

OLIVEIRA, Leandro Dias de ; MASCARENHAS, Gilmar. A Cidade do Prazer: Impactos da Urbanização Turística em Cabo Frio. In: $X$ ENTBL Encontro Nacional de Turismo dom Base Local, 2007, João Pessoa. Identidade Cultural e Desenvolvimento Local. João Pessoa: UFPB, 2007, v. III. p. 583-590.

PORTO-GONÇALVES, Carlos Walter. A geograficidade do social. uma contribuição para o debate metodológico para os estudos de conflitos e movimentos sociais na América Latina. Revista Eletrônica da AGB - Seção Três Lagoas - MS, vol 1, n. 3, ano 3, 2006 [2002]. QUAINI, Massimo. Marxismo e Geografia. Rio de Janeiro, Paz e Terra, 1979.

RIBEIRO, Guilherme. As apropriações do espaço no pensamento de Eric Hobsbawm: a epistemologia da Geografia vista sob o olhar do outro. Dissertação de mestrado. Niterói: PPGE-UFF, 2004. 
- O espaço em Por uma Geografia Nova: resgatando Milton Santos. In: Anais do VI Congresso Brasileiro de Geógrafos, Goiânia, 2004a.

Modernidade e espaço, pós-modernidade e mundo: a crise da Geografia em tempos de globalização. X Colóquio Internacional Geocrítica, Barcelona, maio, 2008.

RIBEIRO, Guilherme; OLIVEIRA, Leandro Dias de;. As Territorialidades da Metrópole no Século XXI: Tensões entre o Tradicional e o Moderno na Cidade de Cabo Frio-RJ. Geo UERJ (2007), v. 3, p. 108-127, 2009.

SANTOS, Milton. Por uma Geografia Nova. São Paulo: Hucitec/Edusp, 1978.

A Urbanização Brasileira. São Paulo, HUCITEC, 1993.

A Natureza do Espaço. Técnica e Tempo. Razão e

Emoção. São Paulo, EDUSP, 1996.

. Por uma outra Globalização: do Pensamento Único à Consciência Universal. Rio de Janeiro: Record, 2000.

Território e Dinheiro. In: PROGRAMA DE PÓS-GRADUAÇÃO EM GEOGRAFIA - PPGEO. Território Territórios. Niterói/RJ, UFF/AGB, 2002.

SMITH, Neil. Desenvolvimento Desigual. Rio de Janeiro: Bertrand Brasil, 1988 [1984].

SOJA, Edward. Geografias Pós-Modernas: a reafirmação do espaço na teoria social crítica. Rio de Janeiro: Jorge Zahar Editor, 1993 [1992].

SOUZA, Marcelo José Lopes de. O Território: sobre Espaço e Poder, Autonomia e Desenvolvimento. In: CASTRO, Iná Elias de, CORRÊA, Roberto Lobato, GOMES, Paulo César (orgs.). Geografia: Conceitos e Temas. Rio de Janeiro: Bertrand Brasil, 1995.

VEIGA, José E. da. A Face Territorial do Desenvolvimento. In: Encontro Nacional de Economia, 27., 1999, Anais. Belém, p. 1301-1318, 1999.

VIRILIO, Paul. O Espaço Crítico e as Perspectivas do Tempo Real. São Paulo: Editora 34, 1993 [1984]. 